\title{
VIEWPOINT
}

\section{Congenital coronary artery dilatation}

\section{S Chakrabarti, E Thomas, J G C Wright, J J Vettukattil}

Heart 2003;89:595-596

\begin{abstract}
Although dilated coronary arteries are uncommon in children, three cases are presented which, even more unusually, were not associated with Kawasaki's disease
\end{abstract}

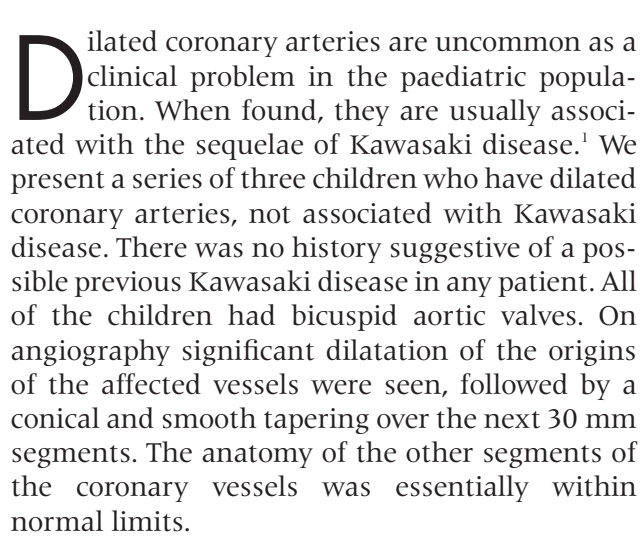

\section{CASE 1}

A newborn infant with antenatal diagnosis of dysplastic aortic valve and aortic regurgitation had evidence of a bicuspid aortic valve, aortic stenosis, and dilated coronary arteries on echocardiography. An angiogram at 9 years of age (fig 1) confirmed the dilatation of the coronary arteries. The child has been asymptomatic to date, with mild aortic stenosis and regurgitation.

\section{CASE 2}

A newborn infant with antenatal diagnosis of small left ventricle had additional diagnoses of a perimembranous ventricular septal defect (VSD), subaortic stenosis, bicuspid aortic valve, and persistent ductus arteriosus (PDA) in the postnatal

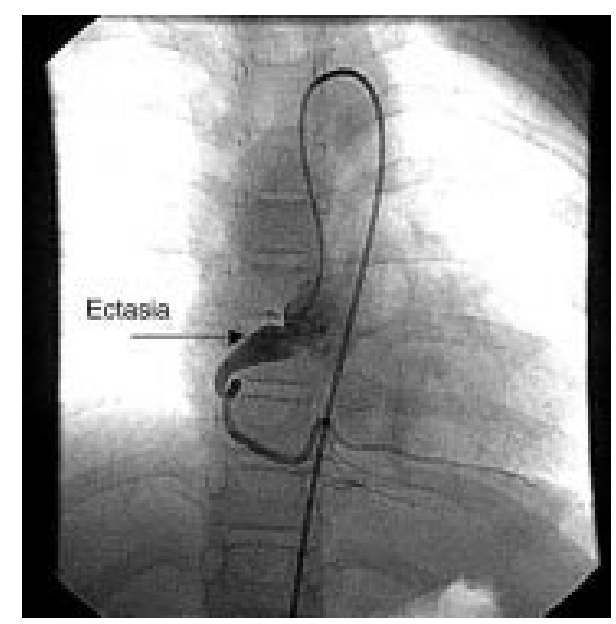

Figure 1 Angiogram of case 1. period. Ectasia of coronary artery origins were also noted in the postnatal scans. After undergoing resection of the subaortic stenosis and closure of the VSD and PDA, he is haemodynamically fine with mild residual subaortic stenosis and aortic regurgitation. The angiogram (fig 2) shows the ectasia of the coronary arteries.

\section{CASE 3}

A newborn infant was diagnosed as having coarctation of the aorta along with bicuspid aortic valve and subaortic stenosis. The baby had a subclavian flap repair. Over years of follow up evolving aortic stenosis and regurgitation were observed. Coronary dilatation was also suspected and confirmed on angiography (fig 3). There was no history of a possible Kawasaki-like illness during the entire period in follow up.

\section{DISCUSSION}

Coronary ectasia has been defined as distension of a part of the artery which is more than $150 \%$ of the diameter of an adjacent unaffected segment. ${ }^{2}$ Some authors have suggested that involvement of the whole vessel should be termed "ectasia", while partial involvement is better called "aneurysm". ${ }^{3}$ Apart from association with Kawasaki disease and coronary fistulae, the aetiology of coronary dilatation in the paediatric age group is not very clear. It has been associated with coronary atherosclerosis, vasculitides ${ }^{4}$ (polyarteritis nodosa and Takayasu's disease), trauma, ${ }^{5}$ and hyperlipidaemia ${ }^{6}$ in the adult population.

Abbreviations: PDA, persistent ductus arteriosus; VEGF, vascular endothelial growth factor; VSD, ventricular septal defect

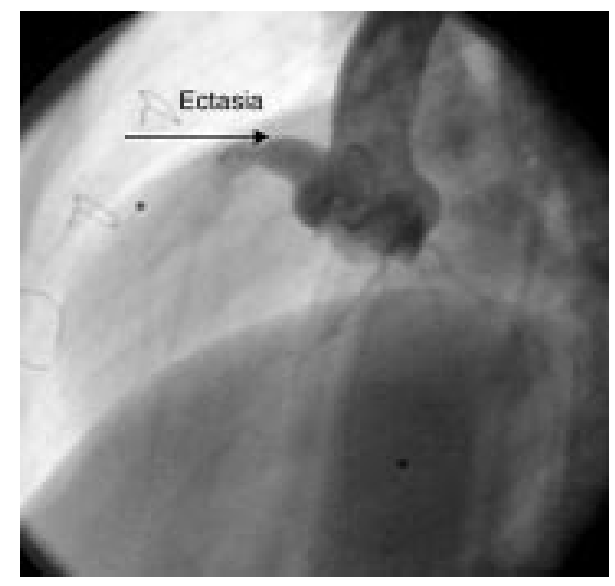

Figure 2 Angiogram of case 2. 


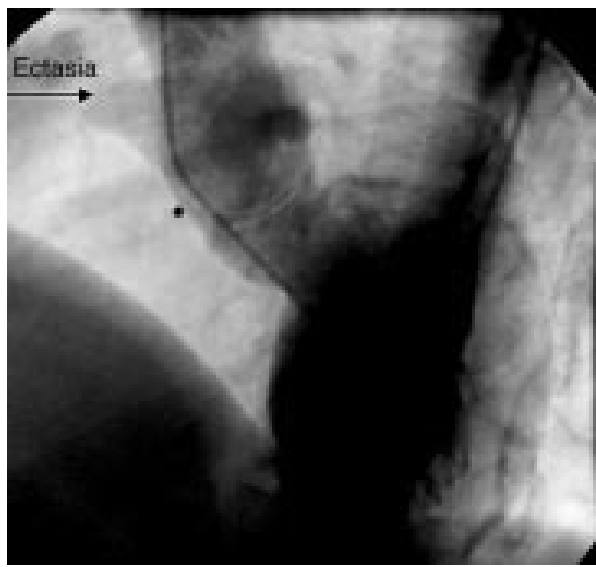

Figure 3 Angiogram of case 3.

Interestingly, only the right coronary artery is involved in all our cases. All of the lesions were conical with a wide opening at the aortic end and smoothly tapering to the normal direction of the distal segment of the coronary artery.

Dilated segments are thought to change the rheology of blood in the affected vessel. Sluggish or turbulent blood flow may then predispose to myocardial ischaemia and its sequelae, including sudden death. ${ }^{7}$ The risk of ischaemic events is increased, regardless of the status of coexisting coronary lesions. ${ }^{8}$

It is unclear why patients develop dilatation of the coronary arteries. It has been postulated that vascular endothelial growth factor (VEGF), which increases in response to an inflammatory state, ${ }^{9}$ may play a role in the pathogenesis of coronary artery lesions in Kawasaki disease. This hypothesis would not be tenable in our series. It is possible that inherent weakness of the aortic wall predisposes to the pathogenesis of these lesions. Bicuspid aortic valve has been associated with serious abnormalities of the ascending aorta, including aortic dilatation, aneurysm, dissection, and coarctation. A common underlying developmental defect of the aortic valve and the ascending aorta has also been suggested..$^{10}$

We postulate that an eccentric jet of blood from the bicuspid aortic valve into the coronary ostia leads to the initiation and then progression of these lesions. None of these patients had coexistent aortic root dilatation to explain the extension of the pathology into the coronary origins. As our patients are young, it is likely that they may have the substrate for aortic dilatation, and accelerated juxta-ostial dilatation is still a possible pathologic process. Even an undiagnosed Kawasaki event in the past is unlikely to be a plausible explanation, with the compelling association of the bicuspid aortic valves in all the three patients. Moreover, in two out of our three patients, the lesion was detected soon after birth.

The natural history of these lesions is not fully known. It is very likely that these patients have an increased risk of ischaemic coronary disease. On the other hand, bicuspid aortic valve is one of the most common congenital heart anomalies in the general population. Such coronary dilatations, though rare, may actually cause significant morbidity and mortality by the virtue of the number of patients having bicuspid aortic valves. We suggest that patients with bicuspid aortic valves (especially those with an eccentric jet) need to be on periodic follow up for early detection and management of these lesions.

\section{Authors' affiliations}

S Chakrabarti, E Thomas, J J Vettukattil, Southampton University Hospital, Southampton, UK

J G C Wright, Birmingham Children's Hospital, Birmingham, UK

\section{REFERENCES}

1 Runge M S, Stouffer G A, Sheahan R. Sudden cardiac death in a teenager: a review of Kawasaki disease. Am J Med Sci 1998;315:273-8.

2 Swaye PS, Fisher LD, Litwon P, et al. Aneurysmal coronary artery disease. Circulation 1983;67:134-8

3 Markis JE, Joffe CD, Cohn PF, et al. Clinical significance of coronary arterial ectasia. Am J Cardiol 1976;37:217-22.

4 Demopoulos V P, Olympios CD, Fakiolas CN, et al. The natural history of aneurysmal coronary artery disease. Heart 1997;78:136-41.

5 Loring WE. Multiple arterioslerotic aneurysms of coronary arteries. Arch Pathol 1955:59:449-52

6 Sudhir K, Port TA, Amidon T M, et al. Coronary heart disease/platelet activation/myocardial infarction: increased prevalence of coronary ectasia in heterozygous familial hypercholesterolemia. Circulation 1995:91:1375-80

7 Takahashi K, Ohyanagi M, Ikeoka K, et al. Clinical course of patients with coronary ectasia. Cardiology 1999;91:145-9.

8 Befeler B, Aranda JM, Embi A, et al. Coronary artery aneurysms. Study of their etiology, clinical course and effect on left ventricular function and prognosis. Am J Med 1977;62:597-607.

9 Freeman AF, Shulman ST. Recent developments in Kawasaki disease. Current Opinion in Infectious Diseases 2001;14:357-61.

10 Bonderman D, Gharehbaghi-Schnell E, Wollenek G, et al. Mechanisms underlying aortic dilatation in congenital aortic valve malformation. Circulation 1999:99:2138-43.

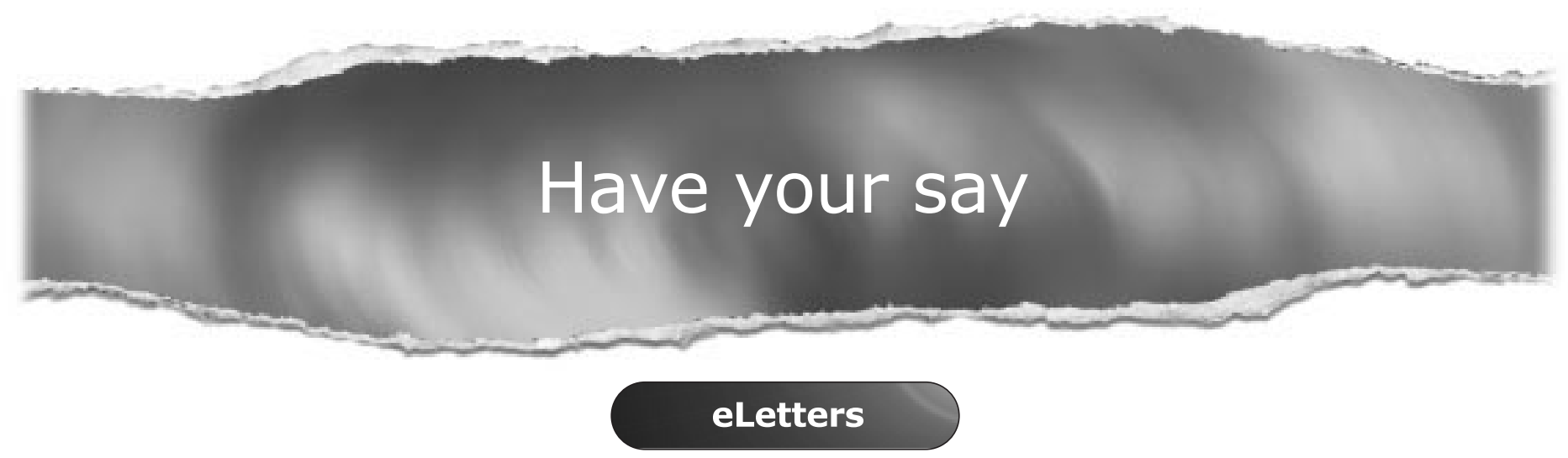

If you wish to comment on any article published in Heart you can send an eLetter using the eLetters link at the beginning of each article. Your response will be posted on Heart online within a few days of receipt (subject to editorial screening). 